\title{
Zur Natur der Bence-Jones-Proteine
}

\author{
Von Friedrich Lohss und Josef Wollensak \\ Aus der Medizinischen Universitätsklinik und Poliklinik Tübingen \\ (Direktor: Professor Dr. H. BENnhold) \\ (Z. Naturforschg. 14 b, 328 - 340 [1959]; eingegangen am 11. September 1958)
}

Herrn Professor Bennhold zum 65. Geburtstag

\begin{abstract}
Drei B e n c e-J o n es - Proteine mit den Sedimentationskonstanten 4,5, 4,0 und 3,7 bzw. 3,6 S werden durch Ammonsulfat-Fraktionierung in elektrophoretisch reiner Form dargestellt, ebenso zwei Myelom-Globulin-Fraktionen derselben Patienten mit $\gamma$-bzw. $\beta_{\mathbf{2}}$-Globulin-Beweglichkeit.

Die untersuchten B.J.-Proteine besitzen einen erheblich niedrigeren Kohlenhydratgehalt als die Myelom-Globuline derselben Patienten oder normales $\gamma$-Globulin.

Alle untersuchten B.J.-Proteine erweisen sich als relativ einheitliche Antigene, mit den Myelom Globulinen derselben Patienten kommen stärkere, mit normalen Humanserum-Globulinen, vor allem $\gamma$-Globulin, schwächere Präzipitin-Reaktionen zustande. Eine immunbiologische Identität unter den drei B.J.-Proteinen besteht nicht, der Grad der jeweiligen Antigenverwandtschaft ist verschieden.

Nach erschöpfender Absättigung der Antiseren mit normalem Humanserum oder $\gamma$-Globulin können bei den untersuchten B.J.-Protein- und Myelom-Globulin-Antiseren Restantikörper nachgewiesen werden, die nur eine Spezifität gegenüber dem homologen Antigen besitzen. In einem Fall gelingt der immunbiologische Nachweis von B.J.-Protein im Patientenserum.

Aus den vorliegenden und früheren Untersuchungen kann geschlossen werden, daß die Globulinsynthese bei der K a h l e r schen Erkrankung variabel ist.
\end{abstract}

Etwa bei der Hälfte aller Myelom-Kranken ${ }^{1,2}$ können im Urin B ence-Jones (B.J.)-Proteine nachgewiesen werden, die bei neutralem oder leicht saurem Milieu zwischen 45 und $58^{\circ} \mathrm{C}$ ausfallen, um sich bei höherer Temperatur wieder zu lösen. Ferner können B.J.-Proteine durch ihre Molekülgröße charakterisiert werden, die im allgemeinen kleiner ist als die des Serumalbumins. Durch Ultrazentrifugierung wurden von verschiedenen Autoren ${ }^{1-5}$ Sedimentationskonstanten zwischen $s_{20}=2,8$ und 4,6 S ermittelt. Die elektrophoretische Wande-

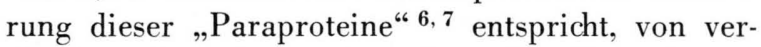
einzelten Ausnahmen abgesehen, dem Bereich normaler $\beta$ - oder $\gamma$-Globuline ${ }^{8-12}$.

Nach früheren Aussalzungen ${ }^{1}$ und neueren physikochemischen Untersuchungen ${ }^{4,5,11,13}$ bestehen zwischen verschiedenen B.J.-Proteinen erhebliche individuelle Unterschiede. Da eine B.J.-Proteinurie

1 A. B. Gutman, in: Advances in Protein Chemistry IV, 195 (1948) ; E. F. Ossermann u. D. P. Lawlor, Amer. J. Med. 18, 462 [1955].

2 F. Wuhrmann u. Ch. Wunderly, Die Bluteiweißkörper des Menschen, B. Schwabe \& Co, Basel 1957.

${ }^{3}$ F. W. Putnam u. B. Udin, J. biol. Chemistry 202, 727 [1953].

${ }^{4}$ L. Korngold u. R. Lipari, Cancer [Bruxelles] 9, 262 [1956].

5 R. W. Rundles, G. R. Cooper u. R. W. Willet, J. clin. Invest. 30, 1125 [1951].

${ }^{6}$ K. Aprtz, Virchow's Arch. pathol. Anatom. Physiol. klin. Med. 306, 631 [1940].

7 H. Bennhold, Klin. Wschr. 31, 388 [1953]. häufig, nach l. c. ${ }^{14}$ sogar stets mit einer gewöhnlichen Proteinurie einhergeht, ist ein u. U. gereinigtes und gut definiertes Untersuchungsmaterial Voraussetzung für eindeutige Befunde.

In der vorliegenden Arbeit wird über Untersuchungen an drei B.J.-Proteinfraktionen berichtet, die sich von Spuren anderer mitausgeschiedener Proteinfraktionen leicht befreien ließen. Gleichzeitig wurden vergleichende Untersuchungen mit den entsprechenden Myelomglobulinen sowie mit normalen Serumproteinen durchgeführt.

\section{Material und Methoden}

1. Die B.J.-Proteinfraktionen wurden von 3 Myelomkranken gewonnen, deren wesentliche klinische Daten aus Tab. 1 ersichtlich sind.

Es sei besonders darauf hingewiesen, daß die Zusammensetzung der Serumproteine in jedem Fall verschie-

8 A. B. Gutman, D. H. Moore, E. B. Gutman, V. McClellan u. E. A. Kabat, J. clin. Invest. 20, 765 [1941].

9 S. S. B Backman u. B. D. Davis, J. clin. Invest. 22, 545 [1943].

10 F. Wuhrmann u. Ch. Wunderly, Bull. Schweiz. Akad. Med. Wiss. 6, 254 [1950].

11 F. W. Putnam u. P. Stelos, J. biol. Chemistry 203, 347 [1953].

12 St. Sandkühler u. F. Hugentobler, Z. klin. Med. 148, 603 [1951].

13 H. F. Deutsch, J. biol. Chemistry 221, 97 [1955].

14 F. Hartmann, Dtsch. Arch. klin. Med. 196, 161 [1949]. 


\begin{tabular}{|c|c|c|c|c|c|c|c|}
\hline Nr. & $\begin{array}{l}\text { Name } \\
\text { Alter }\end{array}$ & $\begin{array}{l}\text { Lokalisation von } \\
\text { Myelomherden }\end{array}$ & $\begin{array}{c}\text { BSG } \\
\text { (Wester- } \\
\text { green) }\end{array}$ & Sternalpunktat & $\begin{array}{l}\text { Gesamt- } \\
\text { eiweiß } \\
\text { (Serum) } \\
{\left[\mathrm{g}_{\mathrm{o}}\right]}\end{array}$ & $\begin{array}{cl}\text { Serumelektrophorese } \\
\text { Abb. } & \text { relativ. } \% \\
& \mathrm{~A} \alpha_{1} \alpha_{2} \beta \gamma\end{array}$ & $\begin{array}{l}\text { tägliche } \\
\text { Protein- } \\
\text { aus- } \\
\text { scheidung }\end{array}$ \\
\hline 1. & Z. 63 & Wirbelsäule & $125 / 130$ & $\begin{array}{l}\text { polymorphzellige } \\
\text { Plasmazellen }\end{array}$ & 13,0 & $\begin{array}{rl}23 & 35 \\
5 & 64\end{array}$ & $2-5 \mathrm{~g}$ \\
\hline 2. & L. 77 & $\begin{array}{l}\text { Schädelkalotte, } \\
\text { Wirbelsäule, } \\
\text { Femur }\end{array}$ & $146 / 152$ & , & 10,0 & $\begin{array}{lll}27 & 4 & 8 \\
61 & 0\end{array}$ & ca. $3 \mathrm{~g}$ \\
\hline 3. & B. 56 & $\begin{array}{l}\text { Schädelkalotte, } \\
\text { Scapula, Rippen, } \\
\text { Wirbelsäule, } \\
\text { Darmbein, Femur. }\end{array}$ & $134 / 152$ & , & 6,3 & $\begin{array}{rll}46 & 7 & 11 \\
8 & 37\end{array}$ & $3-7 \mathrm{~g}$ \\
\hline
\end{tabular}

Tab. 1. Klinische, röntgenologische und klinisch-chemische Untersuchungsergebnisse bei den Myelom-Patienten.

den war. Beim Patienten Z. handelte es sich um ein typisches $\gamma$-, beim Patienten L. um ein $\beta_{2}$-Myelom, während beim Patienten B. nur eine für ein Myelom nicht unbedingt charakteristische $\gamma$-Globulinerhöhung gefunden werden konnte. Im Serum des Patienten L. war neben der stark vermehrten $\beta$-Globulin-Komponente elektrophoretisch kein $\gamma$-Globulin zu entdecken, auch immunelektrophoretisch konnte mit normalem HumanSerum-Kaninchen-Antiserum ebenfalls keine $\gamma$-Globulinbande an typischer Stelle gefunden werden (Abb. $1^{*} \mathrm{a}$ ). Doch darf man bereits nach Abb. 1 b vermuten, daß das $\beta_{2}$-Myelom-Globulin mit normalem $\gamma$-Globulin eine immunologische Verwandtschaft besitzt, da sich mit einem Antiserum gegen das $\beta$-Myelom-Serum auch beim Normalserum eine schwächere $\gamma$-Globulinbande darstellte (Abb. 1 b).

Inwieweit die große Präzipitationslinie des MyelomSerums im $\beta_{2}$-Bereich eine immunbiologische Verwandtschaft mit der neuerdings beschriebenen und im elektrischen Feld ähnlich beweglichen Fraktionen $\beta_{2} \mathrm{~A}, \mathrm{~B}$ oder $\mathrm{M}^{\mathbf{1 5}, 16}$ besitzt, wird Gegenstand weiterer Untersuchungen sein.

Über zwei ähnlich gelagerte Myelomfälle mit „Agammaglobulinämie“, die in unserer Klinik beob-

* Abb. 1 und folgende Ouchterlony-Tests s. Tafel S. 336 a u. b.

15 P. Burtin, L. Hartmann, I. Heremans, I. I. Scheidegger, F. Westendorp-Boerma, R. Wieme, Ch. Wunderly, R. FaUvert u. P. Grabar, Rev. franç. d'Études clin. biol. II, 161 [1957]. achtet wurden, ist früher berichtet worden ${ }^{17}$. Bei einem weiteren Myelomfall mit $\alpha_{2}$-Globulinvermehrung hatten wir elektrophoretisch weder $\beta$-, noch $\gamma$-Globuline gefunden. Anscheinend ist das Vorliegen einer erworbenen „Defektdysproteinämie“ 18 bei der K a h le r schen Krankheit keine Seltenheit.

Bei den ausgeschiedenen B.J.-Proteinen konnte man zunächst noch Spuren von Proteinen schnellerer elektrophoretischer Beweglichkeit nachweisen. Wir stellten größere Mengen gereinigter B.J.-Proteine durch deren wiederholte Ausfällung in 50- bis 55-proz. gesättigter Ammonsulfatlösung in der Nähe des Neutralpunktes und anschließende Zentrifugierung dar, wobei gleichzeitig eine Abtrennung der Begleitproteine erzielt wurde. Die maximale Fällung aller B.J.-Proteine erfolgte in Übereinstimmung mit Versuchen von Deutsch ${ }^{19}$ bei einer Ammonsulfat-Sättigung von etwa 55 Prozent. Bei der anschließenden Dialyse gegen fließendes und letztlich destilliertes Wasser blieben die Proteine praktisch vollständig in Lösung. Sie zeigten infolge Adsorption von Urinfarbstoffen zunächst eine graugelbe Farbe, waren aber nach 5-tägiger Dialyse fast farblos, beim Gefriertrocknen erhielt man nun weiße, in Wasser wieder gut lösliche Präparate. Die Reindarstellung des

16 E. Martin u. J. J. Scheidegger, Bull. Acad. Suisse Sci. Méd. 13, 526 [1957].

17 F. Lohss, A. Hillmann-Elies u. G. Hillmann, Z. Naturforschg. 8 b, 619 [1953].

18 H. Bennhold, Verh. dtsch. Ges. inn. Med. 62, 657 [1956].

19 H. F. Deutsch, J. biol. Chemistry 221, 97 [1955]. 
$\gamma$-Myelom-Globulins Z. erfolgte nach einem früher bewährten Verfahren ${ }^{20}$ durch Kombination von Äthanolfraktionierung in der Kälte ${ }^{21}$ mit Aussalzung durch Ammonsulfat und anschließender mehrtägiger Dialyse gegen gepufferte, 0,9-proz. Kochsalzlösung. Das $\beta_{2}$ Myelom-Globulin L. wurde durch 3-malige Aussalzung in 40-proz. Ammonsulfatlösung isoliert in Analogie zu früher beschriebenen ähnlichen Proteinen ${ }^{17}$. Beide Myelom-Globuline erschienen in isoliertem Zustand bei der Elektrophorese als eine einzige, scharfe Bande. Auf die Präparation des $\gamma$-Globulins aus dem Serum des Patienten B. wurde verzichtet, da es sich elektrophoretisch nicht wesentlich von einem gewöhnlichen $\gamma$-Globulin unterschied. Als normales $\gamma$-Globulin wurde zum Vergleich eine hochgereinigte Präparation der Behring. Werke verwendet.

Laufende Elektrophoresen zur Kontrolle der Präparationen wurden nach dem materialsparenden Verfahren von Grassmann und HanNig ${ }^{22}$ durchgeführt, bei $p_{\mathrm{H}} 8,6$, Barbitursäurepuffer, Ionenstärke $0,1,1 \mathrm{~mA}$. Weitere Überprüfungen der elektrophoretischen Wanderungsgeschwindigkeit und Einheitlichkeit erfolgten in der T i s e li u s - Apparatur bei Proteinkonzentrationen zwischen 0,8 und $1,2 \%, p_{\mathrm{H}} 8,6$ Ionenstärke $0,11,20 \mathrm{mAm}$ père.

Die Sedimentationskonstanten wurden in der analytischen Phywe-Ultrazentrifuge bei $50000 \mathrm{U} / \mathrm{Min}$. entsprechend einem Schwerefeld von $180000 \mathrm{~g}$ durchgeführt. Die Eiweißkonzentrationen betrugen hierbei etwa $0,2 \%$ in 0,9-proz. gepufferter Kochsalzlösung.

Zur Stickstoffbestimmung kam die übliche $\mathrm{Kjel}$ $\mathrm{d}$ a h l - Technik zur Anwendung.

Die Hexosen der einzelnen Proteinfraktionen wurden mit der Orcinreaktion von Tillmanss und Philippi ${ }^{23}$ ermittelt, nach der Modifikation von Sørensen und Havgaard $^{24}$. Dabei wurden $1 \mathrm{~cm}^{3}$ Proteinlösung, 2 bis $12 \mathrm{mg}$ Protein enthaltend mit $1 \mathrm{~cm}^{3}$ 2-proz. Orcinlösung (2 $\mathrm{g}$ Orcin, $80,0 \mathrm{~cm}^{3} \mathrm{H}_{2} \mathrm{O}$ und $20,0 \mathrm{~cm}^{3} \mathrm{H}_{2} \mathrm{SO}_{4}$ konz. p. A. Merck ad $100,0 \mathrm{~cm}^{3}$ ) sowie mit $15 \mathrm{~cm}^{3}$ Reaktionsschwefelsäure (6 Vol. $\mathrm{H}_{2} \mathrm{SO}_{4}$ konz. p. A. Merck und 4 Vol. dest. Wasser) versetzt, 20 Min. im Wasserbad bei $80^{\circ}$ erhitzt, abgekühlt und sofort im Zeiß-Spektrophotometer gemessen. Als Standard wurde eine GalaktoseMannose-Lösung im Verhältnis 1:1 verwendet, deren Absorptionsmaximum nach der Orcinreaktion bei $420 \mathrm{~m} \mu$ lag. Auch die Absorptionsmaxima der untersuchten Proteine entsprachen nach der Orcinreaktion dem Bereich einer Wellenlänge von $420 \mathrm{~m} \mu$. Der Kohlenhydratgehalt wurde jeweils auf die Proteinmenge berechnet, der eine Stickstoffbestimmung und der Eiweißfaktor 6,25 zugrunde gelegt war. Zur Gewinnung von Antiseren wurden Kaninchen, 1 Tier insgesamt bis

20 A. Hillmann, G. Hillmann u. F. Lohss, Z. Naturforschg. 8 b 28 [1953] ; F. Lohss, F. Methfessel u. G. Hillmann, Z. Naturforschg. 8 b, 288 [1953].

21 E. I. Cohn, F. R. N. Gurd, D. M. Surgenor, B. A. Barness, R. K. Brown, G. Derouaux, J. M. Gillespie, F. W. Kahnt, W. F. Lever, C. H. Liv, D. Mittelman, R. F. Mouton, K. Schmid u. E. Uroma, J. Amer. chem. Soc. 72, 465 [1950].

22 W. Grassmann u. K. Hannig, Naturwissenschaften 37, 496 [1950]. zu $200 \mathrm{mg}$, mit alaun-präzipitierten Antigenen in steigender Menge durch ca. 15 i. v. Injektionen in 3-tägigen Abständen immunisiert. Die Antiseren gegen B.J.Proteine oder Myelom-Globuline gaben in keinem Falle mit Humanalbumin eine erkennbare Trübungs- oder Flockungsreaktion. Quantitative Präzipitations-Versuche wurden nach der Technik von Heidelberger und KenDALL ${ }^{25}$ bei konstanten Antikörper- und steigenden Antigenmengen durchgeführt. Ein Ansatz enthielt 1,0 bis $1,5 \mathrm{~cm}^{3}$ Antiserum je nach Antikörpergehalt und vorhandenen Serummengen, Antigen in steigender Menge, $0,9 \%$ Kochsalzlösung mit $m / 100$-Phosphatpuffer $p_{H} 7,0$ ad $2,5 \mathrm{~cm}^{3}$. Die gemischten Ansätze wurden $1 / 2$ Stde. bei $37^{\circ} \mathrm{im}$ Wasserbad und 24 Stdn. im Eisschrank bei $4^{\circ}$ gehalten, anschließend in üblicher Weise dreimal gewaschen, der Niederschlag in $n / 1-\mathrm{NaOH}$ gelöst und sein N-Gehalt nach $\mathrm{K}$ jeld a h l bestimmt. Bei den meisten Versuchen wurden weitere qualitative Ringtests an den Überständen zur Prüfung auf Antigen und Antikörper durchgeführt. Die Äquivalenzzone ist in den folgenden Kurven mit einem Pfeil bezeichnet.

Qualitative Agardiffusions-Plattentests kamen nach der Ouchterlony-Methode ${ }^{26,27}$ bei folgender modifizierter Technik zur Anwendung: Petrischalen von $9 \mathrm{~cm}^{3}$ Durchmesser wurden mit $20 \mathrm{ml} 1-1^{1 / 2}$-proz. heißem Agar (Danager, Lessing u. Co.) in 0,9-proz. Kochsalzlösung beschickt, $p_{\mathrm{H}} 7-7,5$; der Agar enthielt Cialit $1: 10000$. Aus dem erkalteten Agar wurden Löcher von $7 \mathrm{~mm}$ Durchmesser nach Schablonen ausgestanzt und durch Zugabe von 0,2 $\mathrm{cm}^{3}$ heißen Agars Bassins zur Aufnahme von Antigen oder Antikörper gebildet. Bei den Versuchen wurden diese mit $0,3 \mathrm{~cm}^{3}$ Antiserum gefüllt oder mit $0,1 \mathrm{~cm}^{3}$ einer 1-proz. Antigenlösung. Anschließend wurden die Platten bei Zimmertemperatur in eine feuchte Kammer gestellt, die Banden traten bei den rasch diffundierenden B.J.-Proteinen optimal schon nach 2-3 Tagen auf, bei Globulinen meist nach 4 bis 5 Tagen. Die Photographie erfolgte bei diffusem Tages licht (Adox-Film, K.B. 14).

Die Absorptionen der Antiseren erfolgten u. a. mit $4 \%$ (also $1: 4$ verdünntem) $\gamma$-Globulin (Behring) bzw. mit normalem Humanmischserum in 3 Stufen an 3 verschiedenen Tagen, bewußt mit so großen Mengen, daß Antikörper-Verdünnungen von $1: 1,75$ entstanden, die bei der quantitativen Präzipitin-Reaktion immer, bei den qualitativen Tests nach Möglichkeit durch größere Antiserum-Mengen ausgeglichen wurden. Schon bei der zweiten Absorption zeigte sich nur noch ausnahmsweise eine Trübung oder Flockung. Bei der Absättigung der Antikörper mit weiteren Proteinen wurde sinngemäß so verfahren, daß je $1 \mathrm{~cm}^{3}$ Antiserum sukzessiv $25 \mathrm{mg}$ des entsprechenden Proteins in konzentrierter Lösung

23 J. Tillmanns u. K. Philippi, Biochem. Z. 215, 36 [1929].

24 M. Sørensen u. G. Haugaard, Biochem. Z. 260, 247 [1933].

25 M. Heidelberger u. F. E. Kendall, J. exp. Medicine 61. 563 [1935]; 62, 697 [1936].

26 Ö. Ouchterlony, Ark. Kemi 26 B, 14 [1948]; Acta patho]. microbiol. scand. 32, 231 [1953].

27 L. Konngold, J. Immunology 77, 19 [1956]. 
zugesetzt wurden. In den folgenden Abbildungen der Ouchterlony-Tests werden die verschiedenen Antigene oder Antikörper der peripheren Bassins mit a, b, c, d usw. bezeichnet, der Einfachheit halber ist nur a beschriftet, die Bezeichnungen der übrigen Bassins ergeben sich aus der alphabetischen Reihenfolge im Uhrzeigersinn.

Immunelektrophoresen wurden nach der Mikromethode von Scheidegger ${ }^{28,29}$ durchgeführt. Hierbei erfolgten die Elektrophoresen auf Objektträgern mit gereinigtem Agar ${ }^{30}$ mit $0,02 \mathrm{~cm}^{3}$ Antigenlösung, bei denen auch $0,02 \mathrm{~cm}^{3}$ unverdünntes, normales Kontrollserum aufgetragen war. Das jeweilige Antiserum $\left(0,07 \mathrm{~cm}^{3}\right)$ diffundierte von der mittleren Rinne und führte zu den typischen Präzipitations-Banden. Die indirekte Photographie ohne Film und ohne Anfärbung konnte bei normalen Serumproteinen optimal nach $36 \mathrm{Stdn}$. erfolgen, nachdem der jeweilige Objektträger mit 0,9-proz. Kochsalzlösung überschichtet war. Die B.J.-Proteine zeigten wie bei der $\mathrm{Ouchterlony-}$ aufsteigend

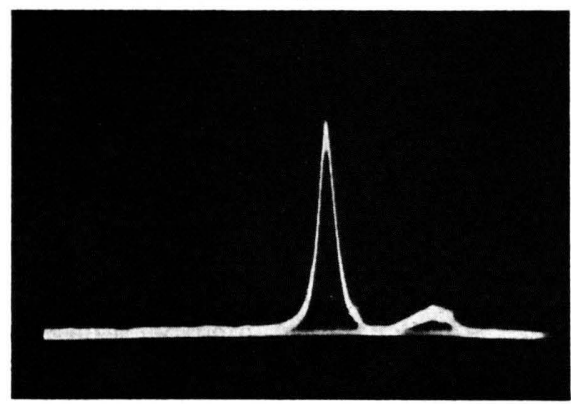

Methode eine erheblich raschere Diffusion, so daß Aufnahmen schon nach $12 \mathrm{Stdn}$. erforderlich waren, und ein Vergleich mit normalen Serumproteinen bei dieser Technik erschwert war. Deshalb wird über solche Versuche erst später berichtet werden können *.

\section{Versuchsergebnisse}

\section{Papier-und Tiselius - Elektrophoresen}

Bei der Papier- und T is eli u s-Elektrophorese wanderten die isolierten B.J.-Proteine $\mathrm{Z}$. und $\mathrm{L}$ als einheitliche Fraktionen mit einer Geschwindigkeit, die etwa dem normalen $\beta_{2}$-Globulin entspricht (vgl. Abb. 2 a und 2 b). Abb. 3 a zeigt das Serum des Patienten Z. mit dessen ausgeschiedenem und iso-

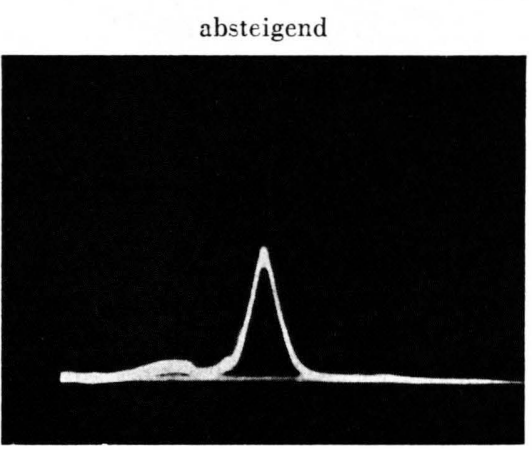

Abb. 2. T i s e li u s - Elektrophoresen der isolierten B e n c e - J o n e s - Proteine. a) B.J.-Protein Z. $s_{20}=4,5 \mathrm{~S}$.
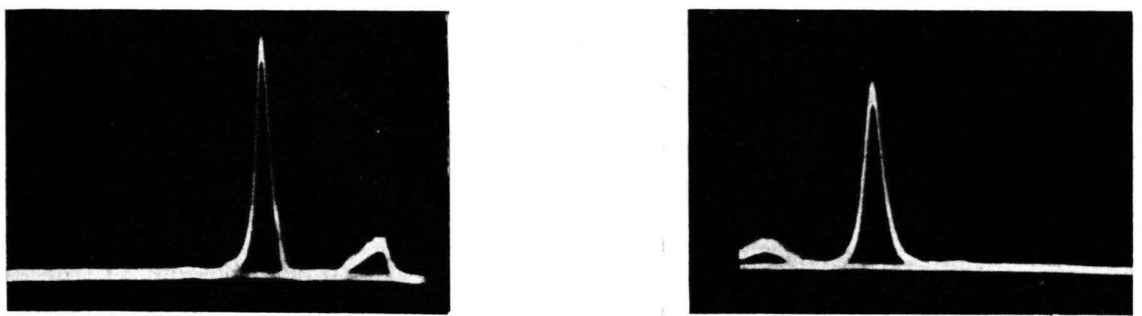

b) B.J.-Protein L. $s_{20}=4,0 \mathrm{~S}$.
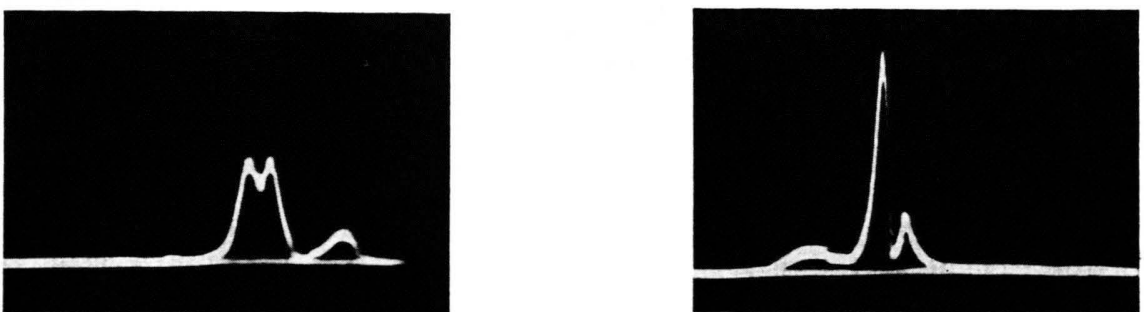

c) B.J.-Protein B. $s_{20}=3,7$ und 3,6 S.

28 P. Grabar u. C. A. Williams, Biochim. biophysica Acta [Amsterdam] 10, 193 [1953].

29 I. I. Scheidegger, Int. Arch. Allergy 7, 103 [1955].
30 H. E. Schultze u. G. Schwick, Behringwerke Mitt. 1957, 33.

* F. Lohs, VII. Colloquium St. Jans Hospitaal, Brügge. 


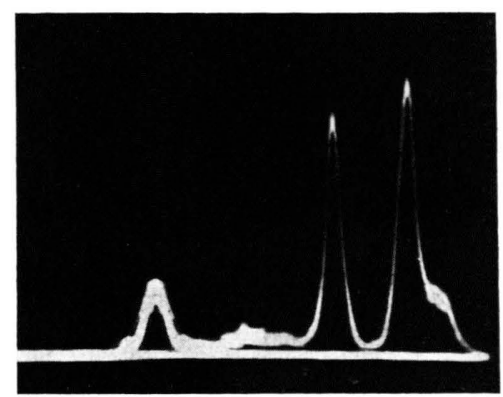

Abb. 3. T i s e l i u s - Elektrophoresen der Myelom-Seren mit Zusatz der ausgeschiedenen isolicrten B.J.-Proteine. a) Serum Z. mit B.J.-Protein Z. Letzteres hat die Beweglichkeit von $\beta_{2}$-Globulin.

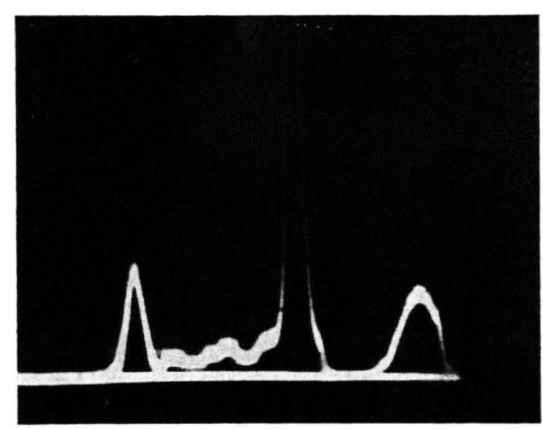

b) Serum L. mit B.J.-Protein L. Das B.J.-Protein im $\beta_{2}$-Globulinbereich kann elektrophoretisch von der $\beta_{2}$-MyelomGlobulin-Bande nicht differenziert werden.

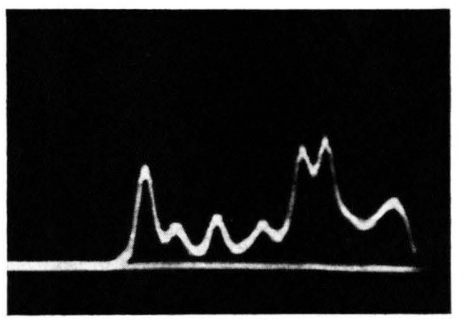

c) Serum B. mit B.J.-Protein B. Letzteres erscheint zweigipflig im $\beta_{2^{-}}$und $\gamma_{1}$-Globulin-Bereich.

lierten B.J.-Proteingemisch, wobei sich die Bande des B.J.-Proteins von der des Myelom- $\gamma$-Globulins deutlich trennt. Bei einem analogen Versuch (Abb. 3 b) ergab sich, daß das zum Serum L. zugesetzte B.J.-Protein L. genau dieselbe elektrophoretische Wanderungsgeschwindigkeit besitzt, wie das im Serum stark vermehrte $\beta_{2}$-Myelomprotein (vgl. auch Tab. 1). Es werden damit von Ossermans ${ }^{1}$ und RIvA ${ }^{31}$ erhobene Befunde bestätigt, wonach die bei

${ }^{31}$ G. Riva, Das Serumeiweißbild, Verlag H. Huber, Bern und Stuttgart 1957, S. 335.

92 E. L. Smith, D. M. Brown, M. L. McFadden, V. BüttnerJANUSCH u. B. V. JAGER, J. biol. Chemistry 216, 601 [1955]. der Kahlerschen Krankheit vermehrten Serumund Urinproteine derselben Patienten im elektrischen Feld eine gleiche oder auch verschiedene Wanderungsgeschwindigkeit besitzen können. Das B.J.Protein B. erschien bei der Papierelektrophorese als eine einheitliche, allerdings ungewöhnlich breite Bande, die Tis elius-Elektrophorese ergab 2 abgrenzbare Fraktionen, von denen die eine der Beweglichkeit des $\beta_{2}$-Globulins, die andere der von $\gamma_{1}$-Globulin zugeordnet werden kann. In dem Elektrophorese-Versuch, der in Abb. $3 \mathrm{c}$ wiedergegeben ist, wurde dieses B.J.-Protein des Patienten B. ebenfalls seinem entsprechenden Serum zugesetzt.

\section{Ultrazentrifugierung}

In der Ultrazentrifuge erwies sich das B.J.-Protein Z. mit einer Sedimentationskonstanten von $s_{20}=4,5 \mathrm{~S}$ als einheitlich. Beim weitaus größten Teil des B.J.-Proteins L. konnte ebenfalls eine einzige Konstante von 4,0 S ermittelt werden, ein kleiner Anteil, über dessen Natur wir bisher nichts Sicheres aussagen können, war nicht sedimentierbar. Im Sedimentations-Diagramm des B.J.-Proteins B. konnten 2 etwa gleich große Komponenten gefunden werden mit den Konstanten 3,7 und 3,6 S, die möglicherweise den auch in der Elektrophorese (Abb. 2c) sich nur wenig voneinander unterscheidenden Banden entsprechen.

\section{Bestimmungderproteingebundenen $\mathrm{Hex}$ os en}

Es konnte schon früher gezeigt ${ }^{17,20}$ und von anderen Autoren bestätigt werden ${ }^{32-34}$, daß alle Myelom-Globuline gebundene Kohlenhydrate enthalten. Nach l. c. ${ }^{33}$ besteht normales $\gamma$-Globulin aus einer kohlenhydrat-ärmeren $7 \mathrm{~S}$ - und einer $5-8 \%$ betragenden kohlenhydrat-reicheren Komponente mit der Sedimentation von $20 \mathrm{~S}$. Mit wenigen Ausnahmen entspricht der Kohlenhydratgehalt von $\gamma$-Myelom-Globulin der normalen 7-S-Komponente des $\gamma$-Globulins, der Gehalt von Myelomglobulinen mit rascherer elektrophoretischer Beweglichkeit ist im allgemeinen höher. Die qualitative Zusammensetzung der gesamten Kohlenhydratfraktion von Myelomglobulinen ist bezüglich Hexosen, Hexos-

33 H. J. Müller-Eberhard u. H. G. Kunkel, J. exp. Medicine 104, 253 [1956].

34 W. G. Rice, J. Lab. clin. Med. 44, 544 [1954]. 
amin, Fucose und Sialinsäure der des normalen $\gamma$-Globulins ebenfalls gleich ${ }^{33}$. Kohlenhydrat-Bestimmungen bei B.J.-Proteinen sind uns nur vereinzelt bekannt geworden. Ossermann ${ }^{1}$ stellte bei mehreren B.J.-Proteinen fest, daß die $\mathrm{S} c \mathrm{~h}$ if f sche Reaktion bei der Papierelektrophorese negativ ausfiel. Deutsch ${ }^{13}$ fand bei einem untersuchten B.J.-Protein kein Hexosamin und mit der Orcin-Reaktion nur $0,24 \%$ Hexosen. Unsere mit der Orcin-Reaktion bei den isolierten Fraktionen gefundenen Ergebnisse sind in Tab. 2 zusammengefaßt.

\begin{tabular}{|l|c|}
\hline & $\begin{array}{c}\mathrm{K} . \mathrm{H} . \\
{[\%]}\end{array}$ \\
\hline 1. $\gamma$-Myelom-Globulin Z. & 1,2 \\
2. $\beta_{2}$-Myelom-Globulin L. & 1,5 \\
3. B. J.-Protein Z. & 0,3 \\
4. B. J.-Protein L. & 0,2 \\
5. B. J.-Protein B. & 0,4 \\
6. $\gamma$-Globulin (Behring) & 1,8 \\
\hline
\end{tabular}

Tab. 2. Kohlenhydratgehalt der untersuchten Globuline und B.J.-Proteine (Orcin-Reaktion).

Auffallend ist auch bei unseren Untersuchungen der niedrige Kohlenhydratgehalt aller B.J.-Proteine, er beträgt nur etwa ${ }^{1 / 5}$ der beiden MyelomglobulinFraktionen oder des bei $\gamma$-Globulin gefundenen Werts.

4. Immunbiologische Untersuchungen

Von mehreren Autoren ${ }^{35-39}$ wurde auf die enge Verwandtschaft der Myelom-Globuline zu normalem $\gamma$-Globulin hingewiesen. Dies hat sich auch in den vorliegenden qualitativen (Abb. 4) und quantitativen (Abb. 5) Untersuchungen wieder bestätigt. Die Präzipitate zwischen $\gamma$-Globulin-Antiserum und Myelom-Globulinen erreichten jedoch nicht die Größenordnung, die mit dem homologen Antigen erzielt wurde. Schon bei der Interpretation früherer ähnlicher quantitativer Versuche ${ }^{36,37}$ waren wir zu dem Schluß gekommen, daß isolierte Myelom-Globuline nicht alle spezifischen Antigen-Gruppierungen des normalen $\gamma$-Globulins besitzen, oder daß diesbezüglich zum mindesten große quantitative Unterschiede im Vergleich zum normalen $\gamma$-Globulin vorliegen müssen, indem einzelne Determinanten stark ver-

35 H. G. Kunkel, R. J. Slater u. R. A. Good, Proc. Soc. exp. Biol. Med. 76, 190 [1951].

36 F. Lohss, E. Weiler u. G. Hillmann, Z. Naturforschg. 8 b, 625 [1953].

37 F. Lohss u. G. Hillmann, Z. Naturforschg. 8 b, 706 [1953]. mehrt und andere vermindert sind. So konnte auch nach Abb. 7 bei den jetzigen Untersuchungen das $\beta$-Myelom-Globulin L. nur einen Teil der $\gamma$-GlobulinAntikörper absorbieren. Beide Myelom-Globuline zusammen absorbierten nach Agardiffusions-Versuchen die meisten, aber nicht alle $\gamma$-Globulin-Antikörper. Unterschiede der Antigen-Zusammensetzung zwischen $\gamma$-Globulin und Myelom-Globulinen konnten

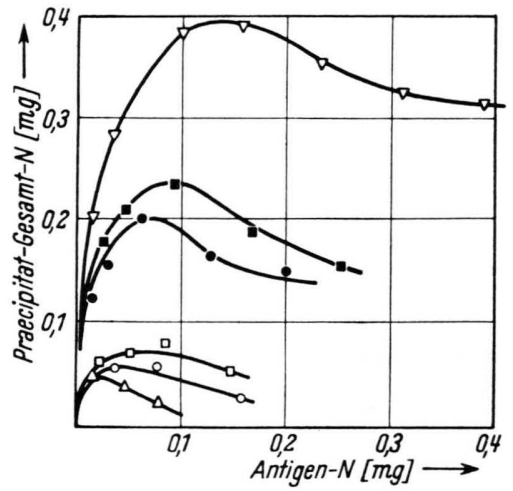

Abb. 5. Quantitative Präzipitin-Reaktion von Antiserum gegenüber normalem $\gamma$-Globulin und: $\nabla$ homologem Antigen, - $\gamma$-Myelom-Globulin Z., - $\beta_{2}$-Myelom-Globulin L., $\bigcirc$ B.J.Protein Z., $\square$ B.J.-Protein L., $\triangle$ B.J.-Protein B.

jetzt auch bei langfristiger Diffusion im Agarplattentest demonstriert werden. Abb. 4 zeigt die Reaktion von $\gamma$-Globulin, normalem Humanserum und die der isolierten Myelom-Globuline in vergleichbarer Konzentration gegenüber $\gamma$-Globulin-Antiserum. Nach einer Versuchsdauer von mehr als 8 Tagen wurde erkennbar, daß nur zwischen den breiten Präzipitations-Banden mit isoliertem $\gamma$-Globulin und dem von Humanserum eine vollständige Identitätsreaktion vorliegt. Die Banden mit den Myelom-Globulinen sind schmäler und gehen nur teilweise in die benachbarten über. Wodurch die schwache, in Abb. $4 \mathrm{~d}$ deutlich abgesetzte Linie mit Humanserum und dem spezifischen $\gamma$-Globulin-Antiserum entstanden ist, können wir nicht sicher entscheiden, vielleicht handelt es sich um die Reaktion eines der physiologischerweise vorkommenden Makroglobuline mit dem $\gamma$-Globulin-Antiserum.

Die 3 vorliegenden B.J.-Proteine gaben im Ringoder Agardiffusions-Plattentest mit normalem Anti-

38 R. J. Slater, S. M. Ward u. H. G. Kunkel, J. exp. Medicine 101, 85 [1955].

39 L. Korngold u. R. Lipari, Cancer [Bruxelles] 9, 183 [1956]. 
Humanserum eine mehr oder weniger deutlich positive Reaktion. Nach unseren bisherigen Untersuchungen kann auf jeden Fall eine Kreuzreaktion mit normalem $\gamma$-Globulin-Antikörper als gesichert gelten (Abb. 6). Diese ist im Agarplattentest nur deshalb schwer demonstrierbar, weil die B.J.-Proteine sehr rasch diffundieren. Ihre Reaktion mit dem $\gamma$-Globulin-Antiserum ist in der Abb. $6 \mathrm{zu}$ einem Zeitpunkt photographisch festgehalten, in dem sich die Bande mit dem normalen $\gamma$-Globulin, dem homologen Antigen, noch nicht optimal entwickelt hat. Es kann nach derselben Abbildung vermutet werden, daß zwischen der Kreuzreaktion von B.J.-Protein L. und der der B.J.-Proteine Z. und B. wahrscheinlich keine Identität vorliegt. Nach längerer Versuchsdauer entwickelte sich hinter der dargestellten Bande mit dem B.J.-Protein L noch eine kleine zweite, die entsprechend ihrer Lage einem Protein entsprechen dürfte, das zum $\gamma$-Globulin eine teilweise Identität besitzt. Bei Absorptions-Versuchen wurden die $\gamma$-Globulin-Antikörper durch die B.J.-Proteine nur teilweise absorbiert (Abb. 7). Alle B.J.-Proteine zusammen besitzen nicht so viele spezifische Gruppen, daß sämtliche Antikörper des $\gamma$-Globulin-Komplexes erschöpft worden wären, im AgardiffusionsTest konnte man mit $\gamma$-Globulin und seinem homologen Antikörper nach Absorption mit allen 3 B.J.Proteinen noch eine deutlich positive Reaktion erzielen.

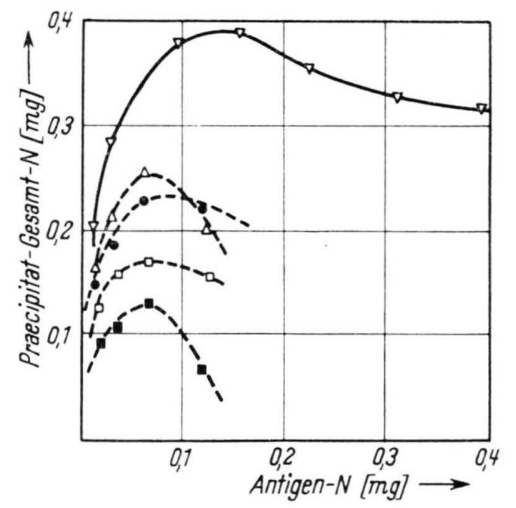

Abb. 7. Quantitative Präzipitin-Reaktion von Antiserum gegen normales $\gamma$-Globulin und:

$\nabla$ homologem Antigen,

- homologem Antigen nach Absorption mit B.J.-Protein Z., homologem Antigen nach Absorption mit B.J.-Protein L., homologem Antigen nach Absorption mit B.J.-Protein B.,

- homologem Antigen nach Absorption mit $\beta_{2}$-MyelomGlobulin L.

Das B.J.-Protein Z. hatte sich als wirksames Antigen erwiesen, es konnte ein hochtitriges Antiserum gewonnen werden, das bei qualitativem Präzipitintest auch mit normalem Humanserum deutlich reagierte. Diese in Abb. 8 a ersichtliche Kreuzreaktion dürfte in erster Linie durch das $\gamma$-Globulin des Serums bedingt sein. Mit dem $\gamma$-Myelom-Globulin Z. kam eine starke Reaktion zustande, bei der die Präzipitations-Bande beider atypischen Proteine desselben Patienten im Sinne einer mindestens teilweisen Identitätsreaktion ineinander übergingen. Mit dem B.J.-Protein L. trat praktisch keine, mit dem B.J.-Protein B. eine deutliche Kreuzreaktion auf. Nach Absorption des Antiserums (Z.) mit den beiden anderen B.J.-Proteinen L. und B. zeigte sich, daß hinsichtlich der Antigenstruktur trotz verschie-

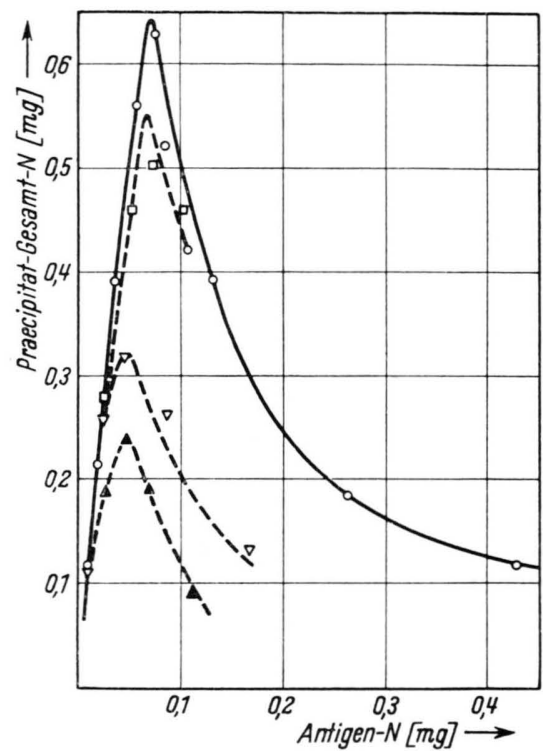

Abb. 10. Quantitative Präzipitin-Reaktion von Antiserum gegen B.J.-Protein Z. und $\bigcirc$ homologem Antigen, $\square--$ homologem Antigen nach Absorption mit B.J.-Protein L., $\Delta--$ homologem Antigen nach Absorption mit B.J.-Protein B., $\nabla--$ homologem Antigen nach Absorption mit normalem $\gamma$-Globulin.

dener elektrophoretischer Wanderung zwischen den B.J.-Proteinen Z. und B. eine größere Verwandtschaft besteht als zwischen den B.J.-Proteinen Z. und L. (vgl. qualitative Versuche Abb. 9 und quantitative Abb. 10).

Nach den Abb. 8 - 11 handelt es sich bei der Präzipitin-Reaktion zwischen dem B.J.-Protein Z. und seinem homologen Antikörper um die eines ziemlich einheitlichen Antigen-Antikörpersystems. Im Agardiffusions-Test (Abb. 8) konnten 2 oder mehr Banden nicht nachgewiesen werden, auch zeigte die quantitative Kurve im Antigen-Überschußbereich 
einen solch starken Abfall zur Abszisse ${ }^{40}$, daß man die B.J.-Proteinfraktion auch nach immunologischen Kriterien als weitgehend einheitlich auffassen darf. Hierfür sprachen außerdem die Analysen an den Überständen, in denen Antigen und Antikörper nebeneinander nicht gefunden werden konnten ${ }^{41}$. Demgegenüber wies der Kurvenverlauf der quantitativen Präzipitin-Reaktion mit dem $\gamma$-MyelomGlobulin und dem B.J.-Protein-Antikörper auf eine andere Reaktionsweise hin, so daß eine nach Abb. 8 a zu vermutende Identität zwischen dem B.J.Protein und dem Myelom-Globulin Z. nach Abb. 11 nicht angenommen werden darf. Die Reaktion mit normalem $\gamma$-Globulin fiel erwartungsgemäß quantitativ geringer aus als die mit dem zugehörigen Mye-

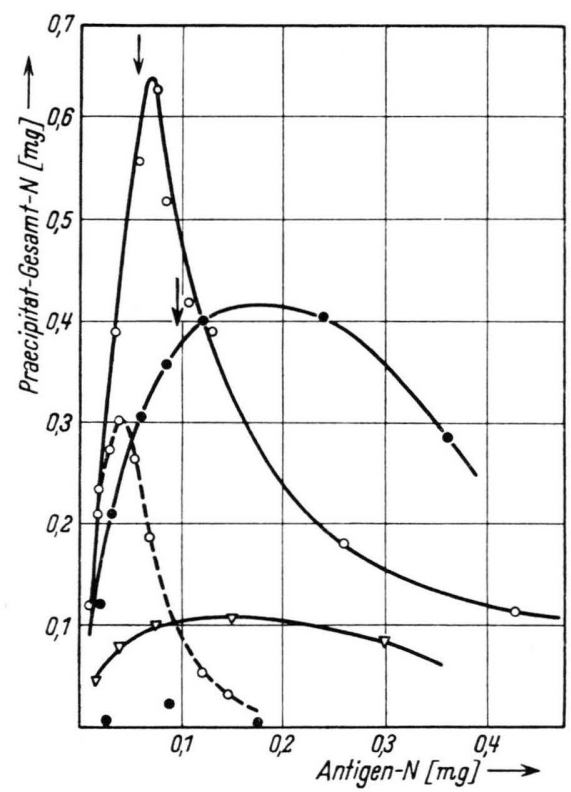

Abb. 11. Quantitative Präzipitin-Reaktion von Antiserum gegen B.J.-Protein Z. und: $\bigcirc$ homologem Antigen, $\bigcirc$ homologem Antigen nach Absorption mit normalem Humanserum (gestrichelt), - homologem Antigen (freie Punkte an der Abszisse) nach Absorption mit $\gamma$-Myelom-Globulin Z., $\gamma$-Myelom-Globulin Z., $\nabla$ Globulin (normal).

lom-Globulin. Nach erschöpfender Absorption des Antiserums mit normalem Humanserum oder $\gamma$-Globulin blieben deutliche Rest-Antikörper nachweisbar, die nach Abb. 10 und 11 etwa die gleiche Größenordnung besitzen und auch im Agarplatten-Test gut demonstrierbar sind (Abb. 12).

41 F. E. Kendall, J. clin. Invest. 16, 921 [1937].

${ }^{40}$ M. Cohn, L. R. Wetter u. H. F. Deutsch, J. Immunology 61, 283 [1949].
Eine vollständige Absorption aller Antikörper des beschriebenen B.J.-Antiserums war jedoch möglich mit dem $\gamma$-Myelom-Globulin desselben Patienten Z. (vgl. freie Punkte an der Abszisse in Abb. 11). Auch im Agarplatten-Test gelang es nicht mehr, eine Präzipitations-Linie mit dem homologen Antigen nachzuweisen, nachdem das B.J.-Antiserum Z. mit dem $\gamma$-Myelom-Globulin Z. absorbiert worden war. Zwischen dem nach Absorption mit normalem Humanserum nachweisbaren Restantikörper und den übrigen B.J.-Proteinen konnte keinerlei Kreuzreaktion mehr gefunden werden, auch mit anderen zur Verfügung stehenden Myelom-Globulinen trat keine nachweisbare Reaktion auf, auffallenderweise auch nicht mit dem $\gamma$-Myelom-Globulin Z., obwohl dieses (in großem Überschuß) eine vollständige Absorption der Antikörper bewirkt hatte (vgl. Abb. 8 b).

Während mit dem B.J.-Protein-Antikörper Z. und dem entsprechenden $\gamma$-Myelom-Globulin Z. eine starke Präzipitin-Reaktion zu erzielen war (Abb. 8 und 11), erwies sich eine solche zwischen dem $\gamma$-Myelom-Globulin-Antiserum und dem B.J.-Protein Z. nur als schwach (Abb. 13). Mit dem B.J.-Protein

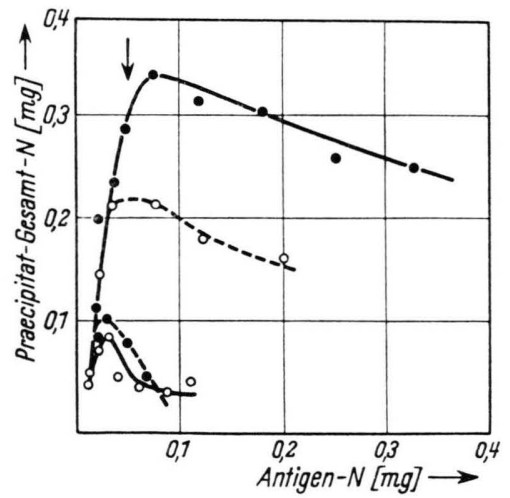

Abb. 13. Quantitative Präzipitin-Reaktion von Antiserum gegen das $\gamma$-Myelom-Globulin Z. und: - homologem Antigen, O- homologem Antigen nach Absorption mit B.J.-Protein Z., - - homologem Antigen nach Absorption mit normalem Humanserum, $\bigcirc$ B.J.-Protein Z.

L. war eine Reaktion nur eben erkennbar. Bei der Absorption des Antiserums mit dem B.J.-Protein desselben Patienten (Z.) konnte nur der kleinere Teil der Myelom-Globulin-Antikörper abgesättigt werden, nach der Absorption des Antiserums mit normalem Humanserum blieb ähnlich wie bei früheren Versuchen ${ }^{36-39}$ ein kleiner Restantikörper nachweisbar, der sich auch bei der AgardiffusionsTechnik bei verlängerter Versuchsdauer nach 5 bis 6 Tagen darstellte (Abb. 14). 
Aus der Abb. 14 geht ferner hervor, daß zwischen dem Antiserum gegenüber dem $\beta_{2}$-Myelom-Globulin L. und dem $\gamma$-Myelom-Globulin Z. keine Präzipitin-Reaktion zustande gekommen ist. Beide Myelom-Globulin-Antigene besitzen aber nach den Abb. 4 und 5 eine teilweise Identität mit normalem $\gamma$-Globulin. Es muß also angenommen werden, daß ihre Reaktion mit dem $\gamma$-Globulin-Antiserum jeweils durch verschiedene Determinanten zustande kam.

Das B.J.-Protein L. erwies sich nach der quantitativen und qualitativen Präzipitin-Reaktion ebenfalls als weitgehend, aber nicht ganz so einheitlich wie das B.J.-Protein Z. Nach längerer AgargelDiffusion war eine kleine zweite Bande erkennbar, deren Antikörper aber mit normalem Humanserum absorbiert werden konnten (Abb. 17). Mit diesem B.J.-Protein-Antiserum und dem $\beta_{2}$-Myelom-Globulin desselben Patienten trat eine starke Kreuzreaktion auf, gegenüber den B.J.-Proteinen Z. und B. kam es zu keiner erkennbaren Reaktion (Abb. 16). Dieser Befund steht in guter Übereinstimmung mit den Ergebnissen früherer Versuche (Abb. 10), nach denen das B.J.-Protein L. mit dem Antiserum gegen das B.J.-Protein Z. im Gegensatz zu dem B.J.-Protein B. kaum reagiert hatte. Mit dem Antiserum gegen das B.J.-Protein L., normalem Humanserum und $\gamma$-Globulin kam eine nachweisbare Kreuzreaktion zustande, eine vollständige Absorption der B.J.Protein-L.-Antikörper durch normale Plasmapro-

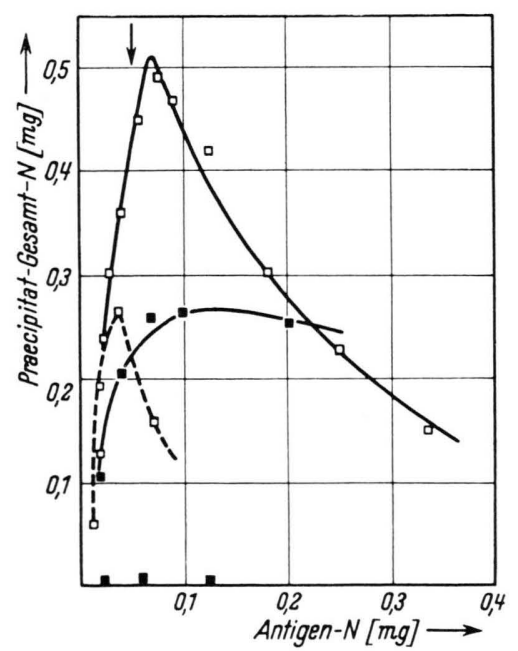

Abb. 15. Quantitative Präzipitin-Reaktion von Antiserum gegen B.J.-Protein L. und: $\square$ homologem Antigen, $\square--$ homologem Antigen nach Absorption mit normalem Humanserum, - $\beta_{2}$-Myelom-Globulin L., (freie Punkte an der Abszisse) homologem Antigen nach Absorption mit $\beta_{2^{2}}$-Myelom-Globulin L. teine gelang ebenfalls so wenig wie bei dem Antiserum gegen das B.J.-Protein Z.

Die quantitativ in Abb. 15 und qualitativ in Abb. 17 dargestellten Restantikörper erwiesen sich wiederum als ausschließlich gegen das B.J.-Protein L. spezifisch, eine Kreuzreaktion ließ sich weder mit den übrigen B.J.-Proteinen erzielen, noch mit dem $\beta_{2}$-Myelom-Globulin L., obwohl letzteres in hoher Dosierung die Restantikörper zu absorbieren vermag.

Bei dem $\beta_{2}$-Myelom-Globulin L. handelt es sich nach unseren Versuchen, ähnlich wie bei dem in seiner Antigenstruktur von ihm verschiedenen $\gamma$-Myelom-Globulin Z. um ein serologisch komplexes Anti-

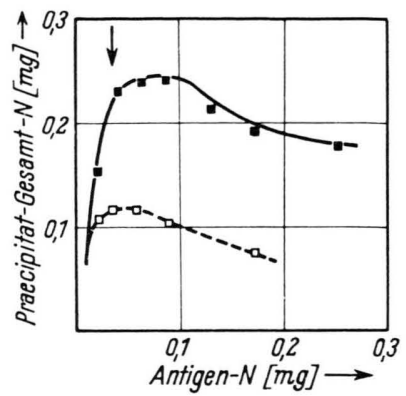

Abb. 19. Quantitative Präzipitin-Reaktion von Antiserum gegen $\beta_{2}$-Myelom-Globulin L. und: homologem Antigen, $\square$ homologem Antigen nach Absorption des Antiserums mit B.J.-Protein L.

gen; in Abb. 18 konnten mindestens 3 Komponenten mit verschiedener Agargel-Diffusion nachgewiesen werden. Das Antiserum gegen dieses MyelomGlobulin reagierte deutlich mit dem B.J.-Protein desselben Patienten L., nicht aber mit den B.J.-Proteinen Z. und B. Nach Absorption mit normalem Humanserum verblieb ein individueller Restantikörper, wie früher beschrieben ${ }^{1,36,38,39}$; irgendeine Kreuzreaktion, auch mit dem B.J.-Protein L., konnte nun nicht mehr nachgewiesen werden.

Auch die Antigenstruktur von B.J.-Protein L. und dem Myelom-Globulin L. ist nur teilweise identisch, wie aus der unvollständigen Absorbierbarkeit des Myelom-Globulin-Antiserums mit dem B.J.-Protein hervorgeht (Abb. 19). Summarisch gesehen zeigten also, abgesehen von der individuell verschiedenen Antigenstruktur die serologischen Reaktionen zwischen dem Myelom-Globulin L. und dem B.J.-Protein L. ähnliche Verhältnisse wie bei dem Patienten $\mathrm{Z}$.

In Abb. 20 ist die (im Gegensatz zu den physikochemischen Befunden) im Ouchterlony-Test 

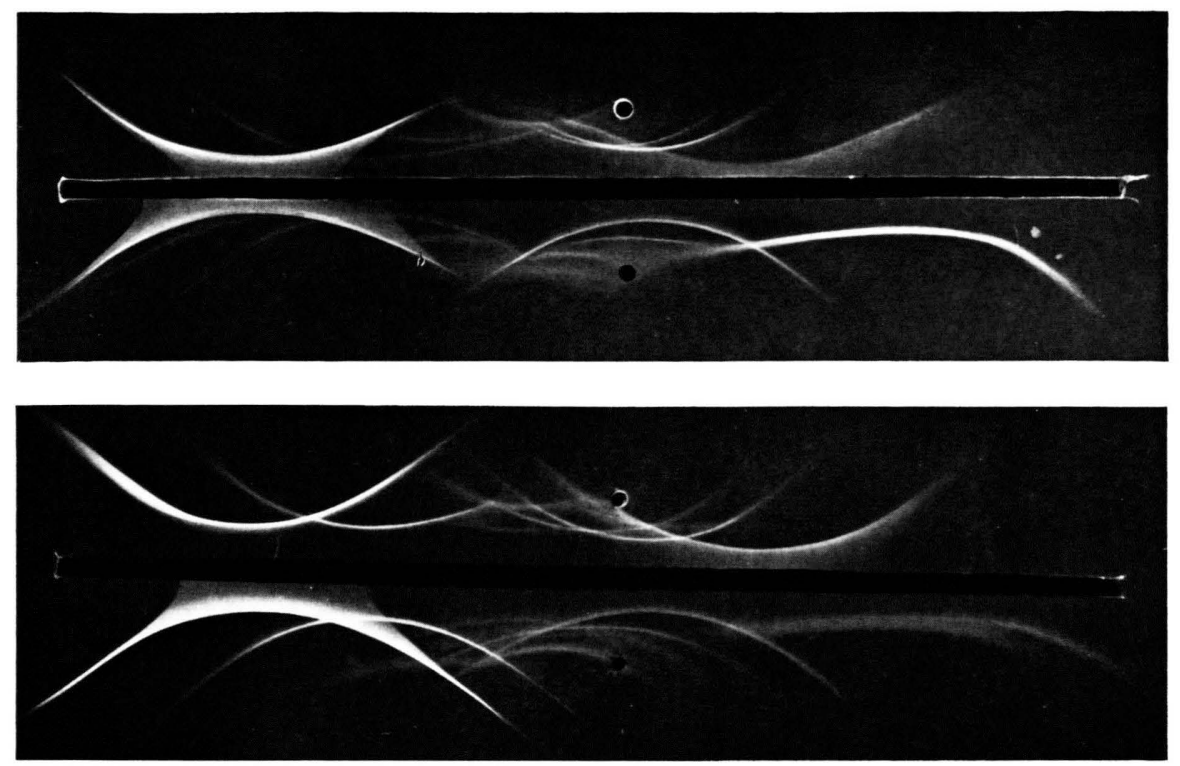

Abb. 1. Immunelektrophoresen des $\beta_{2}$-MyelomSerums L. im Vergleich mit normalem Humanserum.

a) Oben Myelom-Serum L., unten Normalserum. Antikörper: KaninchenAntiserum gegen normales Humanserum. b) Oben Myelom-Serum L., unten Normalserum. Antikörper: KaninchenAntiserum gegen $\beta_{2}$-Myelom-Serum L.

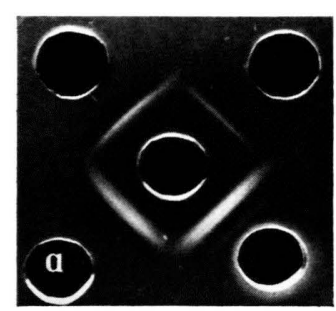

Abb. 4. Reaktion der Myelom-Globuline Z. und L mit Antiserum gegen normales $\gamma$-Globulin im Agardiffusions-Plattentest. Mitte: Normales $\gamma$-Globulin-Antiserum. Antigene: a) Normales $\gamma$-Globulin, b) $\gamma$-Myelom-Globulin Z., c) $\beta_{9}$-MyelomGlobulin L., d) normales Humanserum, $0,025 \mathrm{~cm}^{3}$.

Abb. 6. Mitte: Antiserum gegen normales $\gamma$-Globulin. Antigene: a) homolog, b) B.J.-Protein Z., c) B.J.-Protein L., d) B.J.-Protein B.

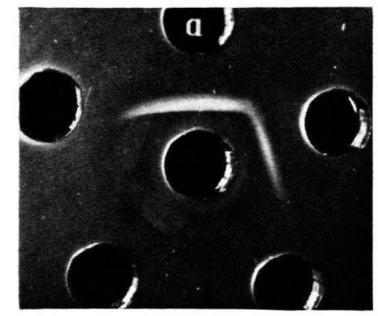

8 a

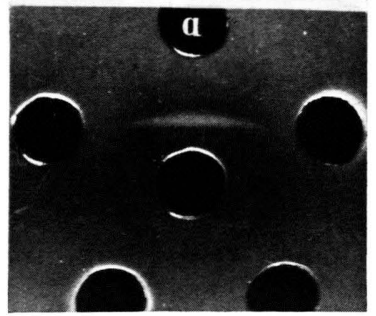

$8 \mathrm{~b}$

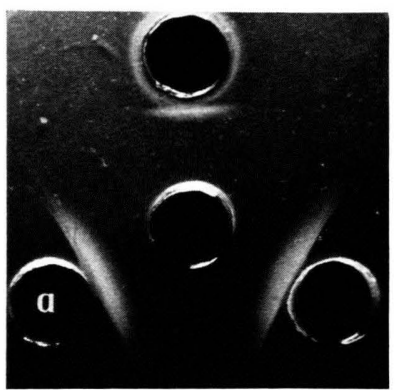

9

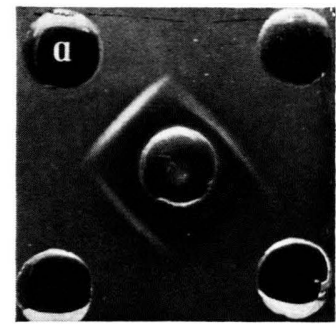

Abb. 8 a. Mitte: Antiserum gegen das B.J.-Protein Z. Antigene: a) homolog, b) $\gamma$-Myelom-Globulin Z., c) B.J.-Protein L., d) normales Humanserum, e) normales $\gamma$-Globulin.

Abb. 8 b. Mitte: Antiserum gegen das B.J.-Protein Z. Nach Absorption mit normalem Humanserum. Antigene: wie 8 a.

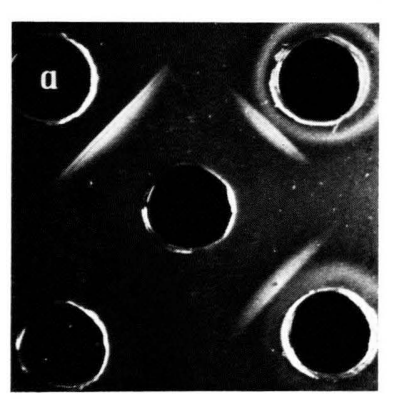

12

Abb. 9. Mitte: Antigen B.J.-Protein Z. Antikörper: a) homolog, b) homolog nach Absorption mit B.J.-Protein B., c) homo$\log$ nach Absorption mit B.J.-Protein L.

Abb. 12. Mitte: Antigen B.J.-Protein Z. Antikörper: a) homo$\log$, b) homolog nach Absorption mit normalem Humanserum, c) homolog nach Absorption mit normalem $\gamma$-Globulin, d)

Antihumanserum (normal, absorbiert mit normalem Humanserum (negative Kontrolle). 


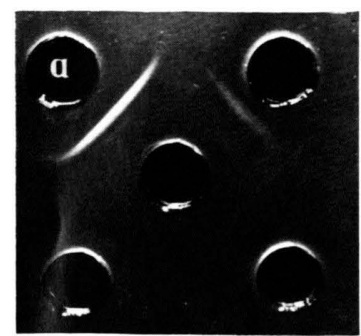

14

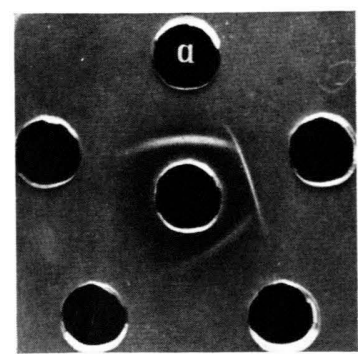

16

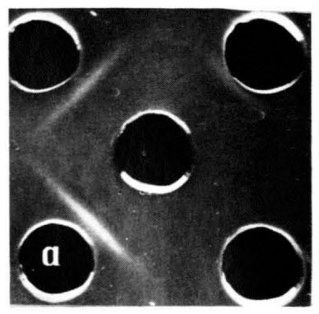

17
Abb. 14. Mitte: Antigen $\gamma$-Myelom-Globulin Z. Antikörper: a) homolog, b) homolog nach Absorption mit normalem $\mathrm{Hu}$ manserum, c) Antiserum gegen $\beta_{2}$-Myelom-Globulin L., d) Humanserum-Antiserum (normal), absorbiert mit homologem Antigen (Kontrolle).
18

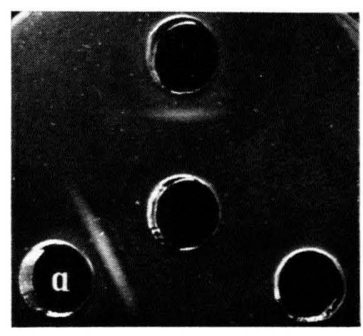

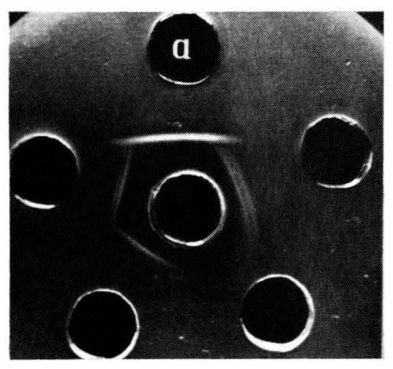

20
Abb. 18. Mitte: Antigen: $\beta_{2}$-Myelom-Globulin L. Antikörper: a) homolog, b) homolog nach Absorption mit normalem Humanserum, c) Humanserum-Antiserum nach Absorption mit normalem Humanserum (Kontrolle).

Abb. 20. Mitte: Antiserum gegen das B.J.-Protein B. Antigene: a) homolog, b) B.J.-Protein Z., c) B.J.-Protein L., d) $\gamma$-Globulin, e) normales Humanserum.

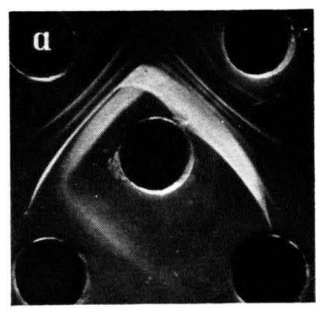

23 a

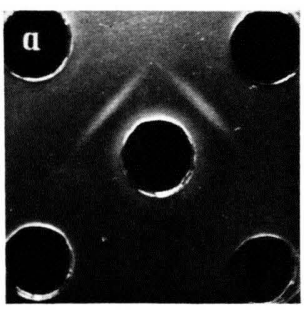

$23 \mathrm{~b}$
Abb. 23 a. Mitte: Antiserum gegen $\beta_{2}$-Myelom-Serum L. Antigene: a) homolog, b) normales Humanserum, c) B.J.-Protein B., d) B.J.-Protein L. (Aufnahme nach 6 Tagen Versuchsdauer).

Abb. 23 b. Mitte: Antiserum wie bei 20 a, nach Absorption mit normalem Humanserum. Antigene: a) homolog, b) $\beta_{2^{-}}$ Myelom-Globulin L., c) B.J.-Protein L.. d) normales Humanserum (Kontrolle).

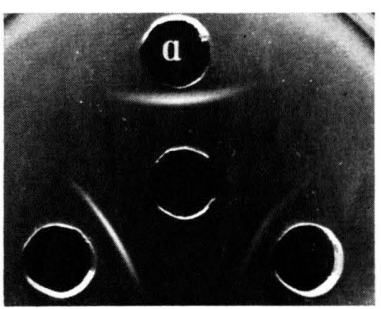

21

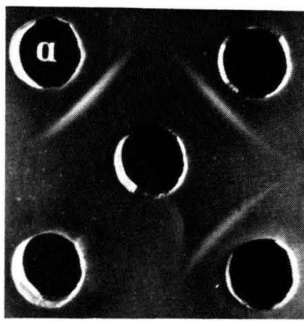

22 a) homolog, b) $\beta_{2}$-Myelom-Globulin L., c) $\gamma$-Globulin (normal), d) B.J.-Protein Z., e) B.J.-Protein B.

Abb. 17. Mitte: Antigen B.J. L. Antikörper: a) homolog, b) homolog nach Absorption mit normalem Humanserum, c) homolog nach Absorption mit normalem $\gamma$-Globulin, d) $\mathrm{Hu}$ manserum-Antiserum (normal) absorbiert mit homologem Antigen (Kontrolle).

Abb. 21. Mitte: Antigen B.J.-Protein B. Antikörper: a) homolog, b) homolog nach Absorption mit B.J.-Protein Z., c) homo$\log$ nach Absorption mit B.J.-Protein L.

Abb. 22. Mitte: Antigen B.J.-Protein B. Antikörper: a) homo$\log$, b) homolog nach Absorption mit $\gamma$-Globulin (normal), c) homolog nach Absorption mit normalem Humanserum, d) Humanserum-Antiserum nach Absorption mit Humanserum (Kontrolle).

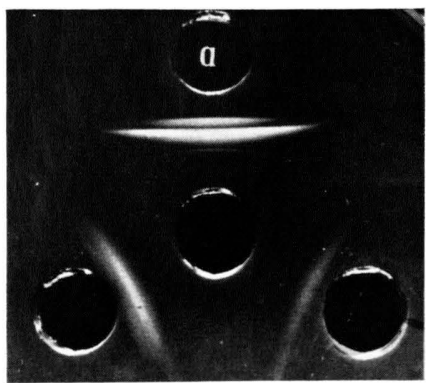

24 körper: a) homolog, b) B.J.-Protein L. nach Absorption mit normalem Humanserum, c) B.J.-Protein L. ohne Absorption.
Abb. 16. Mitte: Antikörper gegen B.J.-Protein L. Antigene:

Abb. 24. Mitte: Antigen: $\beta_{2}$-Myelom-Serum L. $0,1 \mathrm{~cm}^{3}$. Anti- 
völlig einheitliche Reaktion des B.J.-Proteins B. mit seinem homologen Antikörper dargestellt. Entsprechend den bisherigen Befunden konnte mit dem B.J.-Protein Z. eine deutliche, mit dem B.J.-Protein L. keine Kreuzreaktion erzielt werden. Auch $\gamma$-Globulin reagierte im Sinne einer Kreuzreaktion, ebenso wie die $\gamma$-Globulinfraktion des Gesamtserums.

In den Versuchen Abb. 21 wurden Absorptionen mit beiden anderen B.J.-Proteinen durchgeführt in Analogie zu Abb. 9. Das Ergebnis wird durch die Abb. 21 bestätigt und darüber hinaus gezeigt, daß das B.J.-Protein B. gegenüber dem B.J.-Protein Z. eine teilweise Verwandtschaft und auch eigene Determinanten besitzt. Auch bei der Absorption des dritten B.J.-Protein-Antikörpers mit Humanserum oder $\gamma$-Globulin blieben Restantikörper nachweisbar, die sich wiederum als individual-spezifisch erwiesen.

Während von den Patienten Z. und L. zu weiteren Versuchen kein Gesamtserum mehr zur Verfügung stand, konnten mit dem Serum des Pat. L. noch einige ergänzende Befunde erzielt werden. Von besonderem Interesse war nach den bisherigen Ergebnissen ein Vergleich der beiden Restantikörper, die nach Absorption mit normalem Humanserum gegenüber dem $\beta_{2}$-Myelom-Globulin einerseits und dem B.J.-Protein andererseits nachgewiesen werden konnten. Abb. 23 a ist eine Aufnahme des bereits in Abb. 1 demonstrierten $\beta_{2}$-Myelom-Serum-Antiserums im Agardiffusions-Versuch. Gegenüber den verschiedenen Antigenen eines normalen Humanserums kamen nach dieser Darstellung mit dem homologen Antigen-Gesamtserum doch erhebliche Differenzen zustande. Man darf annehmen, daß die stärkste Bande im Versuch 23 a, a mit der des $\beta_{2}$-MyelomGlobulins identisch ist, auch mit dem B.J.-Protein L. war eine Reaktion zu erzielen (Abb. 23 a,d). Mit dem B.J.-Protein B. war keine Reaktion aufgetreten. Nach Absättigung des Antiserums mit normalem Humanserum verblieb ein Restantikörper, der sich in Abb. $23 \mathrm{~b}$ als mit dem bereits beschriebenen $\beta_{2}$-Myelom-Globulin-Restantikörper identisch erwies und auch mit dem B.J.-Protein L. keine Reaktion mehr einging. Somit war auch ein Nachweis von B.J.-Protein im Krankenserum mit Hilfe dieses Antiserums nicht möglich.

Wegen der starken Kreuzreaktion zwischen dem Antiserum gegen das B.J.-Protein L. und dem

42 H. Bence-Jones, Philos. Trans. Roy. Soc. London, Ser. B 138, 55 [1848], zit. n. l. c. ${ }^{31}$.
$\beta_{2}$-Myelom-Globulin L. konnte ein Versuch zum Nachweis des B.J.-Proteins im Krankenserum auch mit Hilfe des B.J.-Protein-Antikörpers nicht ohne weiteres durchgeführt werden. Nach Abb. 24 c bildet das nicht absorbierte B.J.-Protein-Antiserum L. mit dem Myelom-Serum L. 2 größere Banden, von denen eine als Präzipitation mit dem $\beta_{2}$-MyelomGlobulin aufgefaßt werden muß.

Nach Absorption des Antiserums mit normalem Humanserum entsprechend den Versuchen der Abb. 17 konnte aber im $\beta_{2}$-Myelom-Gesamtserum eine kleine Bande nachgewiesen werden, die bei einwandfreien immunbiologischen Kontrollen das Vorkommen von B.J.-Protein im Serum beweist und mit $\operatorname{dem} \beta_{2}$-Myelom-Globulin keine Kreuzreaktion mehr eingeht.

\section{Diskussion}

Die erste bekannte und noch heute zur Diagnostik verwendete Eigenschaft der nach ihm benannten Proteine stammt von Bence-Jones ${ }^{42}$, indem er das ungewöhnliche Verhalten beim Erhitzen beschrieb. Die Hitzereaktion ist aber wohl in der Mehrzahl, nicht aber in allen Fällen typisch ${ }^{11,31}$. Unter den technisch einfacheren Methoden kann hier bereits die weitverbreitete Papierelektrophorese auch bei vorhandener Begleitproteinurie wertvolle Dienste leisten. Das kleinmolekulare und noch symmetrischer als Albumin gebaute ${ }^{11}$ Proteinmolekül wird durch die Niere besonders leicht ausgeschieden. Auch im Tierversuch war eine Nierenpassage mit B.J.-Protein, nicht aber mit normalen Serumproteinen demonstrierbar ${ }^{43}$. So ist es erklärlich, daß in zahlreichen ${ }^{1,2,10,11,31}$ und auch in unseren Fällen sich bei der Elektrophorese eine für die B.J.-Proteinurie charakteristische Zusammensetzung der Harnfraktionen ergab, bei der im Gegensatz zu gewöhnlichen Proteinurien die Bande des Albumins nicht überwiegt. Zur weiteren einfachen Identifizierung einer B.J.-Proteinbande bei der Papierelektrophorese erscheint uns die Anwendung der S c h if f schen Reaktion und die Bestimmung bisher bekannter Kohlenhydrat-Proteinbausteine bei weiteren B.J.-Proteinurien einer Überprüfung wert, da neben den Ergebnissen von Deutsch ${ }^{13}$ auch nach unseren Versuchen der Hexosengehalt der B.J.-Proteine sich von dem zahlreicher normaler ${ }^{44}$ und pathologischer Globu-

43 R. A. Alberty, J. physic. Colloid Chem. 53, 114 [1949].

${ }^{44}$ H. E. Schultze, Scand. J. Clin. Lab. Invest. 10, 135 [1957]. 
line ${ }^{17,20,32-34,45}$ unterscheidet und im Hinblick auf eine mögliche, ähnliche oder identische Wanderungsgeschwindigkeit von B.J.-Proteinen und Globulinfraktionen eine weitere Differenzierungs-Möglichkeit bietet. Während chemische und zahlreiche physiko-chemische Untersuchungen bei verschiedenen B.J.-Proteinen erhebliche individuelle Differenzen ergeben hatten, scheint im niedrigen Kohlenhydratgehalt eine weitere gemeinsame Eigenart vorzuliegen. Darüber hinaus ist eine signifikante Differenz wesentlicher Bausteine auch insofern bemerkenswert, als das gehäufte Vorkommen von Hyperglobulinämie und B.J.-Proteinurie bei der Kahlerschen Erkrankung einen gemeinsamen Ursprung dieser typischen Serum- und Uroprotein-Fraktionen nahelegen könnte.

In jüngerer Zeit hatten Sedimentations- und Diffusionsbestimmungen gezeigt, daß B.J.-Proteine sich nicht nur bezüglich ihrer Wanderung im elektrischen Feld unterscheiden. Obgleich die Mol.-Gew. in vielen Fällen bei Sedimentationskonstanten von ca. $3 \mathrm{~S}$ um 40000 liegen, können nach zahlreichen Untersuchungen innerhalb der bisher als extrem ermittelten Werte von 24000 und 90000 von Fall zu Fall praktisch alle Größenordnungen vorkommen ${ }^{1-5,8,31,46}$. Nach Studien von Putnam und Miyake ${ }^{47}$ war bei 8 untersuchten B.J.-Proteinen in keinem Fall die Beweglichkeit oder Sedimentation identisch, darüberhinaus lie $\beta$ auch die $N$-ständige Aminosäure-Gruppierung eine Differenzierung von 4 weiteren Typen zu, in 4 Fällen wurden allerdings Asparaginsäure und Glutaminsäure gefunden wie beim normalen $\gamma$-Globulin ${ }^{48}$, in einem Fall Asparaginsäure allein. Neuere Bausteinanalysen ${ }^{49-51}$ und UV-Spektren zeigten neben individuellen Schwankungen wenigstens eine teilweise ähnliche Aminosäuren-Zusammensetzung wie normales $\gamma$-Globulin. Als markanteste Abweichung wurde aber der von Dent und Rose erstmals erhobene Befund ${ }^{53}$ wieder-

45 E. F. Ossermann u. P. Lawlor, Science [Washington] 120, 715 [1954].

46 O. I. TEN Thye, Acta med. scand. 153, 253 [1956].

47 F. W. Putnam u. A. Mryake, Science [Washington] 120, 848 [1954].

48 F. W. Putnam, J. Amer. chem. Soc. 75, 2785 [1953].

49 R. Crokaert, H. Verbruggen u. E. J. Bigwood, Arch. int. Physiol. 60, 558 [1952], zit. nach l. c. ${ }^{12}$.

50 E. Madema, P. van der Schaaf u. T. Huisman, J. Lab. clin. Med. 45, 261 [1955].

51 B. A. Jirgensons, J. Landua u. A. J. Awaparpa, Biochim. biophysica Acta [Amsterdam] 9, 625 [1952].

52 K. Jahnke u. F. Heinzler, Schweiz. med. Wschr. 87, 1559 [1957]. holt bestätigt, daß Methionin bei B.J.-Proteinen fehlt oder der Gehalt signifikant erniedrigt ist (zusammenfassend s. l. c. ${ }^{31}$ ).

Myelom-Globuline besitzen nach den bisher zahlreichen und auch in der vorliegenden Arbeit wiederbestätigten (Abb. 4-6) Untersuchungen trotz ihrer differenten Wanderung vor allem nach immunbiologischen Kriterien eine Verwandtschaft zu den normalen $\gamma$-Globulinen, auch Bausteinanalysen ${ }^{33,34}$ und Bestimmungen der UV-Spektren ${ }^{11,17,20,46}$ haben keine wesentlichen Abweichungen vom normalen $\gamma$-Globulin ergeben. Obgleich außer der hauptsächlichen 7-S-Komponente auch öfters solche mit den Sedimentationskonstanten von 9, 11 und $14 \mathrm{~S}$ beschrieben wurden $1,3,17,20,55,56$, vereinzelt auch mit $3^{57}$ bzw. 4 $\mathrm{S}^{1}$, scheinen die Ergebnisse der Ultrazentrifugierung bei Myelom-Globulinen keine so starke Variabilität aufzuweisen wie bei den B.J.-Proteinen. Daß aber auch bei den Myelom-Globulinen verschiedener Kranker in der Feinstruktur zahlreiche Unterschiede bestehen können, erwiesen schon Analysen der $N$-ständigen Aminosäuren ${ }^{58,59}$. Ferner konnten eingehende immunbiologische Versuche zeigen, daß zwar eine Antigengemeinschaft verschiedener Myelom-Globuline mit dem normalen $\gamma$-Globulin besteht, doch besitzen erstere meist weniger determinante Gruppen als der normale $\gamma$-GlobulinAntigen-Komplex, darüber hinaus wurden bei Myelom-Globulinen auch zusätzliche, neue, individualspezifische determinante Gruppen nachgewiesen. Die in der vorliegenden Arbeit untersuchten Fraktionen verhielten sich ebenso. Bei der jetzt möglichen Übersicht über zahlreiche Untersuchungen darf man eine außerordentliche Variationsmöglichkeit der Zellen annehmen, welche die pathologischen Proteine bilden.

Von verschiedenen immunbiologischen Arbeiten mit B.J.-Proteinen (zusammenfassend s. 1.c. ${ }^{60}$ ) können leider nur wenige zu einem kritischen Vergleich

53 C. F. Dent u. G. A. Rose, Biochem. J. 44, 410 [1949].

54 F. T. Grisola u. P. P. Cohen, Cancer Res. 13, 851 [1953].

55 R. A. KeKwick, Biochem. J. 34, 1257 [1940].

56 I. Waldenström, Advances in internat. Med., Verlag W. Dock und J. Snapper, 1952, S. 389.

57 G. Riva, K. Dialer u. A. Hässig, Helv. med. Acta 18, 401 [1951].

58 G. Braunitzer, A. Hillmann-Elies, F. Lohss u. G. Hillmans, Z. Naturforschg. 9 b, 615 [1953].

59 F. W. Putnam, A. Miyake u. F. Meyer, Fed. Proc. 14, 859 [1955].

60 P. Burlin, L. Hartmann, R. Fauvert u. P. Grabar, Rev. franç. d'Études clin. biol. I, 17 [1956]. 
mit unseren Resultaten herangezogen werden, da z. T. das Antigenmaterial physiko-chemisch nicht eindeutig definiert oder die immunbiologischen Beziehungen zu normalen Serumproteinen nicht abgeklärt waren. Deutsch und Mitarbb. ${ }^{62}$ erzielten mit 2 verschiedenen, physiko-chemisch geprüften B.J.Proteinen ähnliche quantitative Präzipitin-Kurven wie wir. Neben Deutsch ${ }^{62}$ wurde auch von KornGold ${ }^{60}$ sowie von ScheIDEgGeR ${ }^{63}$ eine Kreuzreaktion verschiedener B.J.-Proteine zu normalem $\gamma$-Globulin festgestellt, wie auch wir sie in allen 3 Fällen fanden. Unsere Feststellung, daß eine nähere immunbiologische Verwandtschaft der B.J.-Proteine zu den speziellen Myelom-Proteinen als zu den normalen $\gamma$-Globulinen anzunehmen ist, stimmt ebenfalls mit Ergebnissen von KonNGold ${ }^{60}$ überein. Weitere Verwandtschaften der B.J.-Proteine zu anderen Globulinen haben wir bisher nicht ausgeschlossen und beabsichtigen, zu dieser Frage noch immunelektrophoretische Untersuchungen durchzuführen.

Die zahlreichen, auch in der vorliegenden Arbeit gezeigten qualitativen und quantitativen Kreuz- und Verwandtschafts-Reaktionen der verschiedenen nicht miteinander identischen Proteinfraktionen sind nur dann erklärbar, wenn man beim normalen $\gamma$-Globulin mehrere spezifische antigene Gruppen annimmt. Mit determinanten-ärmeren Myelom- bzw. B.J.-Proteinen konnte ScheIDEgGer ${ }^{63}$ beim normalen $\gamma$-Globulin deren 4, Korngold ${ }^{60} 7$ nachweisen. Ohne daß wir in der vorliegenden Arbeit mit speziellen Versuchsanordnungen diese Frage geprüft haben, muß man nach unseren Versuchen mindestens $5 \gamma$-Globulin-Determinanten annehmen: Die beiden MyelomGlobuline sind nach Abb. 14 miteinander nicht identisch oder verwandt, absorbieren auch zusammen normale $\gamma$-Globulin-Antikörper nicht vollständig. Außerdem besitzen sie mindestens eine Determinante mehr als die zugehörigen B.J.-Proteine Z. und L., von denen feststeht, daß sie untereinander keine, nach Abb. 6 aber eine Verwandtschaft zum normalen $\gamma$-Globulin besitzen.

Neben verschiedenen $\gamma$-Globulin-Determinanten konnten aber auch individual bzw. für jedes einzelne atypische Protein spezifische Determinanten nachgewiesen werden. $\mathrm{Ob}$ diesbezüglich eine immun-

${ }^{61}$ D. H. Moore, E. A. Kabat u. A. B. Gutman, J. clin. Invest. 22, 67 [1943].

${ }^{62}$ H. F. Deutsch, C. H. Kratochuil u. A. E. Reif, J. biol. Chemistry 221, 103 [1955].

es J. J. Scheidegarer u. C. Buzzi, Rev. franç. d'Êtudes clin. biol. II, 895 [1957]. biologische Gruppenverwandtschaft oder -Identität besteht, wird man erst bei der Prüfung eines größeren Untersuchungsmaterials entscheiden können.

Unter Annahme von mindestens $5 \gamma$-GlobulinDeterminanten und der Voraussetzung, daß die untersuchten B.J.-Proteine keine weiteren mit anderen physiologischen Globulinen gemeinsame immunbiologische Gruppierungen besitzen, möchten wir vorläufig folgende schematisierte Übersicht zum Verständnis der schon bei den wenigen untersuchten Proteinfraktionen so vielfältigen Beziehungen geben:

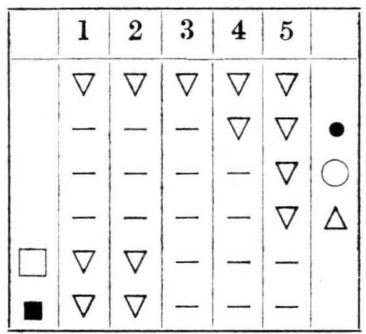

Zahl der $\gamma$-Globulin-Determinanten

$\gamma$-Globulin (normal)

$\beta$-Myelom-Globulin $\mathbf{Z}$.

B.J.-Protein Z.

B.J.-Protein B.

$\beta_{2}$-Myelom-Globulin L.

B.J.-Protein L.

Tab. 3. Schema der Gruppierung von Determinanten normalen $\gamma$-Golublin $(\nabla)$, von untersuchten Myclom-Globulinen und B.J.-Proteinen. Atypische Determinanten sind außerhalb der Spalten 1-5 dargestellt.

Daß die Myelom-Globuline desselben Patienten, dessen B.J.-Restantikörper vollständig absorbieren, ohne daß sie nach der Absorption durch Normalserum mit diesem Restantikörper eine Kreuzreaktion eingehen, möchten wir so erklären, daß die Myelom-Globuline teilweise als inkomplette Antigene wirkten. Eine teilweise inkomplette Reaktion hat auch Deutsch ${ }^{62}$ bei normalen Serum-Globulinen mit B.J.-Protein-Antikörpern beobachtet. Weniger wahrscheinlich erscheint uns die Annahme, daß die zugehörigen Myelom-Globulin-Fraktionen trotz wiederholter Fällung in 40-proz. Ammonsulfat noch Spuren von B.J.-Proteinen enthielten, die erst bei den großen zur Absättigung verwendeten Mengen wirksam wurden.

Man muß also nach unseren Versuchen annehmen, daß sich in einem Myelom-Serum mindestens zwei verschiedene Paraproteine mit verschiedenen spezifischen Determinanten befinden können. Ein ähnlicher Befund wurde vor uns bereits bei einem Makroglobulinämie-Fall von Riva und Mitarbb. ${ }^{57}$ erhoben, wobei das vermehrte Serumglobulin eine Sedimentation von 18,5, das Uroprotein eine solche von $4,5 \mathrm{~S}$ besaß.

Über die Bildung von B.J.-Proteinen sind verschiedene Hypothesen aufgestellt worden. Andere ${ }^{60}$ 
und z. T. auch unsere immunbiologischen Versuche, die eine engere serologische Verwandtschaft zu den Myelom-Globulinen desselben Patienten als zu anderen normalen Globulinen ergeben hatten, stehen nicht unbedingt im Widerspruch zu der Hypothese, daß B.J.-Proteine als Abbauprodukte der MyelomGlobuline aufzufassen sind ${ }^{5}$. Diese Annahme erscheint aber im Hinblick auf die eigenen Determinanten sowie den niederen Methionin- und Kohlenhydratgehalt der B.J.-Proteine nicht wahrscheinlich. Dagegen sprechen vor allem neuere Untersuchungen mit radioaktivem Kohlenstoff ${ }^{64}$, bei denen festgestellt werden konnte, daß B.J.-Protein erheblich rascher und offenbar unabhängig vom Myelom-Globulin gebildet wird. Die entgleiste Proteinsynthese scheint aber wie die der Myelom-Globuline zu vielen Varianten fähig zu sein. Nach unseren Ergebnissen war keines der B.J.-Proteine mit einem anderen immunbiologisch völlig gleich. Die Zahl der Varianten wird sich erst an Hand eines größeren Untersuchungsmaterials bestimmen lassen. Nach anderen ${ }^{60,62,65}$ und unseren Ergebnissen ist eine routinemäßige Diagnostik einer B.J.-Proteinurie mit einem einzigen Antiserum unmöglich.

Wir danken Herrn Professor Bennhold für die Förderung unserer Arbeiten, ebenso Herrn Professor SchaEFER (Max-Planck-Institut für Virusforschung, Tübingen) für seine Ratschläge. Die Papier-Elektrophoresen wurden durch Fräulein Dr. Rотн durchgeführt, die Immunund $\mathrm{T}$ iseli us-Elektrophoresen in Gemeinschaft mit Herrn Dr. Отт und Frau K. Lohss. Ein Teil der Versuche konnte im Rahmen eines Programmes durchgeführt werden, das von der Deutschen For$\mathrm{schung}$ g e m ein s ch af t unterstützt wurde.

${ }^{64}$ F. W. Putnam u. S. Hardy, J. biol. Chemistry 212, 361 [1955]; S. Hardy u. F. W. Putnam, 212, 371 [1955].

65 B. Udin u. F. W. Putnam, Fed. Proc. 11, 271 [1952].

\title{
Versuche zur papierdhromatographischen Trennung einiger im Gehirn von Astacus astacus enthaltenen dhemischen Bestandteile und ihre Wirkung auf den isolierten Meerschweindhen-Darm
}

\author{
Von H. Kunnen und E. Zoch \\ Aus dem Zoologischen Institut und dem Physiologisch-Chemischen Institut der Universität des \\ Saarlandes (Saarbrücken und Homburg/Saar) \\ (Z. Naturforschg. 14 b, 340—341 [1959]; eingegangen am 21. Januar 1959)
}

\begin{abstract}
Der enteiweißte wäßrige Gehirnextrakt von Astacus astacus wird papierchromatographisch auf Aminosäuren, Amine und Zucker untersucht. Die Wirkung der identifizierten Aminosäuren auf den isolierten Meerschweinchen-Darm wird näher beschrieben.
\end{abstract}

In früheren Arbeiten war über einen Stoff aus dem Gehirn des Flußkrebses (Astacus astacus) berichtet worden, der die Bewegungen isolierter Därme und Ovidukte von Insekten und die Bewegungen des isolierten Meerschweinchen-Ileum hemmt ${ }^{1,2}$. In der vorliegenden Arbeit wird der Versuch unternommen, diesen Hemmstoff auf dem Wege der chromatographischen Analyse näher zu bestimmen.

Die papierchromatographische Untersuchung des Gehirnextraktes

Wir exstirpierten die Gehirne von 17 Flußkrebsen und homogenisierten die Organe in $2 \mathrm{ml}$ dest. Wasser. Das Homogenisat wurde 15 Min. bei $5000 \mathrm{U} / \mathrm{min}$ zentrifugiert. Aus dem Zentrifugat entfernten wir die Eiweißstoffe durch Ausfällen mit dem gleichen Volumen 96-proz. Äthanol. Den so behandelten Gehirnextrakt untersuchten wir mit der 2-dimensionalen papier- chromatographischen Methode auf Aminosäuren, Amine und Zucker.

Als Papier wurde S \& S 2043 b benutzt. Als Fließmittel fanden in der 1. Dimension n-Butanol - Eisessig Wasser $(4: 1: 5)$, in der 2. Dimension $\alpha$-Picolin-Eisessig-Wasser (75:2:23) Verwendung.

Mit Ninhydrin als Sprühreagens wurden 15 Flekken nachgewiesen. Von diesen 15 ninhydrin-positiven Substanzen konnten mit Hilfe von Testsubstanzen und speziellen papierchromatographischen Verfahren ${ }^{3}$ sowie durch spezifische Farbreaktionen 14 Substanzen mit Sicherheit identifiziert werden (s. Abb. 1).

In dem von uns untersuchten Extrakt zeigten die Aminosäuren $\alpha$-Alanin, Arginin, Glutamin und Gly-

1 G. Koller, Verh. dtsch. zool. Ges. Tübingen 1954, 18. Suppl. 417 [1955].

2 H. Kunnen, Verh. dtsch. zool. Ges. Erlangen 1955, 19. Suppl. 117 [1956].

3 E. Zoch, Arzneimittel-Forsch. 8, 236 [1958]. 